\title{
Prevalence of depression and anxiety and correlations between depression, anxiety, family functioning, social support and coping styles among Chinese medical students
}

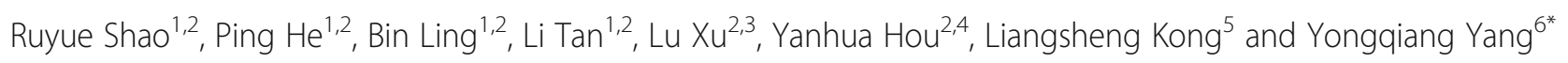

\begin{abstract}
Background: Medical students experience depression and anxiety at a higher rate than the general population or students from other specialties. While there is a growing literature on the high prevalence of depression and anxiety symptoms and about potential risk factors to the prevalence of depression and anxiety symptoms among medical students, there is a paucity of evidence focused on the prevalence of depression and anxiety symptoms and associations with family function, social support and coping styles in Chinese vocational medicine students. This study aims to investigate the prevalence of depression and anxiety symptoms among Chinese medical students and assess the correlation between depression/anxiety symptoms and family function, social support and coping styles.
\end{abstract}

Methods: A sample of 2057 medical students from Chongqing Medical and Pharmaceutical College in China was investigated with a self-report questionnaire, which included demographic information, Zung self-rating depression scale, Zung Self-Rating Anxiety Scale, Family APGAR Index, Social Support Rating Scale and Trait Coping Style Questionnaire.

Results: The prevalence of depression and anxiety symptoms among the medical students was 57.5 and 30.8\%, respectively. Older students( $\geq 20$ years) experienced higher levels of depression and anxiety. More depression and anxiety symptoms were exhibited among students with big financial burden, big study-induced stress and poor sleep quality. Students with large employment pressure showed more anxiety symptoms. Students who live alone or had bad relationship with their lovers or classmates or friends showed higher depression and anxiety scores. Depression and anxiety symptoms had highly significant correlations with family functioning, social support and coping style.

Conclusions: Academic staffs should take measures to reduce depression and anxiety among medical students and to provide educational counseling and psychological support for students to cope with these problems.

Keywords: Depression, Anxiety, Family function, Social support, Coping style, Medical students

\footnotetext{
* Correspondence: fyyyq1984@cqmu.edu.cn

${ }^{6}$ School of Basic Medical Sciences, Chongqing Medical University, No.1 Yixueyuan Road, Yuzhong District, Chongqing 400016, China

Full list of author information is available at the end of the article
}

(c) The Author(s). 2020 Open Access This article is licensed under a Creative Commons Attribution 4.0 International License, which permits use, sharing, adaptation, distribution and reproduction in any medium or format, as long as you give appropriate credit to the original author(s) and the source, provide a link to the Creative Commons licence, and indicate if changes were made. The images or other third party material in this article are included in the article's Creative Commons. licence, unless indicated otherwise in a credit line to the material. If material is not included in the article's Creative Commons licence and your intended use is not permitted by statutory regulation or exceeds the permitted use, you will need to obtain permission directly from the copyright holder. To view a copy of this licence, visit http://creativecommons.org/licenses/by/4.0/ The Creative Commons Public Domain Dedication waiver (http://creativecommons.org/publicdomain/zero/1.0/) applies to the data made available in this article, unless otherwise stated in a credit line to the data. 


\section{Background}

Depression is shown to be one of the most common health problems among university students $[1,2]$. Medical students experience depression at a higher rate than the general population [3] or students from other specialties [4]. Besides depression, many studies have reported high prevalence of anxiety symptoms among medical students [5-8]. About 30\% of medical students suffer from anxiety or depression in Europe [9, 10]. Brazilian studies reported a similar rate, in which 20 to $50 \%$ of medical students were found to present with mental disorders [11].

Undoubtedly, medical training is a stressful process which may contribute to the emergence of depression and anxiety [12, 13]. Academic pressure, workload, financial concerns, sleep deprivation, as well as factors interfering in everyday personal life are stressors factors $[3,14]$. According to a qualitative-quantitative study conducted at a medical college from August 2016 to March 2017, academic pressure was the major concerns identified by the students when asked about the reasons for psychological distress [15]. Almost all participants mentioned that the huge amount of information and high requirements of medical courses is one of the main causes of high mental distress. At the same time, they found that time for sleep and other social activities was very limited, which only further increased the level of distress [15]. Rosenthal et al. also reported that sleep deprivation may expose students to mood disorders [16]. Medical students also emphasized that finance is an important area to concern. Compared with students belonging to higher sociodemographic backgrounds, psychological distress was higher in which belonging to lower and middle sociodemographic backgrounds [15]. Hojat et al. reported that $42 \%$ of first-year and secondyear students at Jefferson Medical College have experienced financial hardships in the past 12 months and consider them to be stressful events in their lives [17]. Wege et al. also reported the association between financial problems with psychosomatic symptoms and poor mental health [18]. Depression and anxiety symptoms can adversely influence medical students, including poor academic performance, school dropout, alcohol and substance abuse, internet addiction and suicidal ideation and attempts [19-23].

At the same time, stress during medical training drives medical students to develop certain skills, resources and strategies to cope with these situations, a phenomenon known as coping [24]. Coping refers to the individual cognitive and behavioral strategies to master, reduce or tolerate the internal and external demands of stressful situations [25]. These coping strategies may be positive or negative [26]. Positive coping is an active coping style that focuses on taking constructive actions and changing the stressful situation, and it is typically associated with problem-solving behavior and effective emotion regulation [27]. In contrast, negative coping is a passive style centered on negative appraisals and emotional expression, escape of stressful situations and social isolation [27]. Studies showed that medical students employ both coping styles [28].

While there is a growing literature on the high prevalence of depression and anxiety symptoms and about potential risk factors to the prevalence of depression and anxiety symptoms among medical students, there is a paucity of evidence focused on the prevalence of depression and anxiety symptoms and associations with family function, social support and coping styles in Chinese vocational medicine students. Additionally, in the Chinese context, the medical education system and medical working environment are somewhat different from those in Western or other Asian countries [29]. Excessive number of patients and relatively insufficient number of doctors has resulted in high workload for Chinese doctors. Increasing tension between doctors and patients in recent years frequently lead to violent attacks against medical professionals and a lack of respect from society. These factors could be the cause of worries and mental disorders in Chinese medical students [29, 30]. Thus, the aim of this study was to investigate the prevalence of depression and anxiety symptoms among Chinese medical students and assess the correlation between depression/ anxiety symptoms and family function, social support and coping styles among Chinese medical student.

\section{Methods \\ Design and participants}

This is a cross-sectional, questionnaire-based descriptive study that was conducted during the year 2018. All medical students from Chongqing Medical and Pharmaceutical College in China were eligible to participate in the study. There were no exclusion criteria. The study was approved by the Ethical Committee of Chongqing Medical and Pharmaceutical College and written informed consent was required from all participants. Participation was voluntary and students were informed about the purpose of the study. Confidentiality was assured and questionnaires were submitted anonymously.

The medical education in mainland China is different from western countries. In China, most undergraduate students are enrolled in medical colleges for a 5-year or 3-year period following high school. 3-year medical education mainly trains doctors at the grassroots level. Chongqing Medical and Pharmaceutical College is a such 3-year medical education college, which enrolls about 3000 students each year, with a total of about 9000 students. 


\section{Instruments}

The self-report questionnaire used in this study consisted of six sections or measures, namely demographic information, Zung self-rating depression scale (Zung SDS), Zung Self-Rating Anxiety Scale (Zung SAS), Family APGAR Index (APGAR), Social Support Rating Scale (SSRS) and Trait Coping Style Questionnaire (TCSQ).

\section{Demographic information}

The demographic section was designed by the research team to collect the general characteristics of medical students, including gender, age, grade, race/ethnicity, place of residence, housing, whether the only child in the family, family characteristics, household income per month, educational levels and occupations of parents, health condition of parents, parents' way of raising, parents' care, financial burden during the study, expectations of parents or family members, physical exercise, appetite status, sleep quality, study-induced stress, employment pressure, self-conceived character, having chronic disease or not, satisfaction of specialty and relationship with lovers and classmates or friends.

\section{The Zung self-rating depression scale (Zung SDS)}

The SDS is a 20 -item scale evaluating mood symptoms in the past 7 days. Each item is scored on a Likert scale ranging from 1 to 4 according to the frequency of symptoms over the past week. The score from each item is calculated to obtain the raw score, and the standard score is equal to the raw score multiplied by 1.25 . Standard Score is classified as: less than 50, no depression; 50-59, minimal to mild depression; 60-69, moderate to marked depression, greater than 70, severe depression [31-33]. A Chinese version of the SDS was administered in the survey. The reliability and validity of the Chinese version of SDS has been confirmed in previous studies $[34,35]$.

\section{The Zung self-rating anxiety scale (Zung SAS)}

The anxiety symptoms among medical students were measured with the SAS, which developed by Zung in 1971 [36]. The SAS questionnaire has 20 self-report questions which were scored on a 4-point Likert scale according to the frequency of symptoms in the past 7 days, ranging from 1 to 4 . The score from each item is calculated to obtain the raw score, and the standard score is equal to the raw score multiplied by 1.25 . The cut-offs for the SAS standard scores were defined as: less than 50, no anxiety; 50-59, minimal to mild anxiety; 60-69, moderate to marked anxiety, greater than 70, severe anxiety [31, 37]. The Chinese version of the questionnaire has been widely used and demonstrates adequate reliability and validity [5, 38-40].

\section{Family APGAR index (APGAR)}

The family APGAR index (APGAR) was developed by Smilkstein [41] and has well established reliability and validity [42]. This scale evaluates a family member's perception of family functioning by assessing his/her satisfaction with family relationships. It includes five parameters: adaptation, partnership, growth, affection and resolve. Three possible answers are allowed("almost always", "sometimes", "hardly ever"), and the score ranges from 0 to 2 points. The points from each item is calculated to obtain the total score. Higher scores indicate better family functioning. A total score of 0-3 suggests severe family dysfunction, 4-6 moderate family dysfunction and 7-10 good family functioning.

\section{Social support rating scale (SSRS)}

The SSRS was originally developed by Xiao Shuiyuan in 1986 for the Chinese population [43]. It has already been widely used in various studies in different Chinese communities and shown to have good validity and reliability [44-46]. It includes 10 items and evaluates social support in the following three dimensions: Objective support, subjective support, and support utilization. Objective support reflects objective, visible or practical support received in the past. Subjective support reflects the individual emotional experience of being respected, supported and understood in the community. Support utilization reflects the pattern of behavior that an individual uses when seeking social support [46]. Items were mostly rated by 4-point Likert scales. Item scores were added up, generating a final score ranging from 12 to 66 . Higher scores indicate stronger social support.

\section{Trait coping style questionnaire (TCSQ)}

The Trait Coping Style Questionnaire (TCSQ) was used to measure coping strategies, including two domains: positive coping (PC) and negative coping (NC). Each domain consists of 10 items. Each item is ranked on a 5point Likert-type scale, ranging from 1(absolutely no) to 5(absolutely yes). The higher the one-dimensional scores, the more positive or negative the coping styles are. The TCSQ was developed among the Chinese population in mainland China and has obtained adequate reliability and validity [47].

\section{Statistical analysis}

All analyses were performed using SPSS 21.0 statistical software package (SPSS Inc., Chicago, Illinois). All statistical tests were two-sided $((p<0.05)$. All demographic data were analyzed and presented as number $(\mathrm{N})$ and percentage (\%). Using Mann-Whitney U-test and KruskalWallis test as appropriate, we compared depression and anxiety severity by demographic variables. Spearman rank order correlation was used to examine correlations 
among depression, anxiety, family function, social support and coping styles.

To explore the independent effect of different variables on depression and anxiety symptoms, hierarchical regression analysis was used. In model 1, all demographic variables were entered. Dummy variables were set for categorical variables before entering the model. In model 2 to 4 , anxiety or depression symptoms, family function, social support were sequentially entered. The results of bivariate correlations showed that the positive coping and negative coping were significantly correlated $(\mathrm{r}=-$ $0.129, p<0.01)$. To avoid problems of multicollinearity, positive coping and negative coping were entered respectively in model 5 . Standardized estimate $(\beta), F, R^{2}$ and $R^{2}$-changes $\left(\Delta R^{2}\right)$ for each model were presented.

\section{Results}

Among the 2057 medical students who participated in this research, 603(29.3\%) were males, while $1454(70.7 \%)$ were females. Their age ranged from 17 to $25(\mathrm{M}=19.76$, $\mathrm{SD}=1.17)$. Demographic characteristics of participants are shown in Table 1. The prevalence of depression and anxiety symptoms among the medical students in the present study was $57.5 \%$ (SDS index score $\geq 50$ ) and $30.8 \%$ (SAS index score $\geq 50$ ), respectively. The mean scores of the SDS and SAS indexes were $51.9 \pm 10.1$ points and $46.9 \pm 7.7$ points, respectively. For depression status, the prevalence of each category was $42.5 \%$ (no depression), $34.7 \%$ (minimal to mild depression), $18 \%$ (moderate to marked depression) and 4.9\% (severe depression). For anxiety status, the prevalence of each category was $69.2 \%$ (no anxiety), $23.9 \%$ (minimal to mild anxiety), 6\% (moderate to marked anxiety) and $0.8 \%$ (severe anxiety).

Comparisons within the various demographic characteristics demonstrated a few significant differences between groups on SDS and SAS scores (Table 2). Older students were more likely to report depression or anxiety symptoms compared to the young students $(p=$ $0.002 ; p=0.001$ ). Depression and anxiety levels showed a non-significant difference by sex. First and second grade students less frequently reported depression or anxiety than did third grade students $(p<0.001)$. There was no difference in depression levels between different places of residence; however, students living in rural area were more likely to report anxiety compared to the students living in urban $\operatorname{area}(p=0.001)$. Living alone was associated with more $\operatorname{depression}(p=0.01)$ and anxiety $(p<$ $0.001)$. Although no significant differences were found among paternal or maternal education with respect to symptoms of depression $((p=0.258 ; p=0.726)$, students whose paternal and maternal educations were low did indicate greater symptoms of anxiety as compared to those whose paternal and maternal educations were high $(p<0.001 ; p=0.003)$. Students who reported that their parents were more authoritarian reported more depression and anxiety symptoms than those who reported that their parents were democracy or laissez-faire $(p<$ 0.001). Students who reported that their parents cared about them and have big expectations on them were less prone to have depression and anxiety symptoms $(p<0.05)$. Students with significant financial burden and studyinduced stress exhibited more depression and anxiety symptoms $(p<0.05)$. Students with large employment pressure were more likely than those with small employment pressure to report anxiety $\operatorname{symptoms}(p<0.001)$. Students had poor appetite and sleep reported more depression and anxiety symptoms than those had good or fair appetite and sleep. Students with introvert character reported more depression and anxiety symptoms ( $p<$ $0.001)$. Bad relationship with lovers or classmates or friends was associated with more depression $(p<0.05)$ and anxiety $(p<0.001)$. The frequency with which students had bad relationship with lovers was nearly 7 times greater in students with severe anxiety (3 of 17, 17.6\%) than in students with minimal to mild anxiety (13 of $492,2.6 \%)$.

Bivariate correlations demonstrated in Table 3 suggested that depression and anxiety symptoms had highly significant correlations with family functioning, social support and coping style. Depression and anxiety were significantly positively correlated with each other $(\mathrm{r}=$ $0.403, p<0.01$ ). Depression significantly negatively correlated with family functioning and all five dimensions (i.e., adaptation, partnership, growth, affection, resolve) ( $\mathrm{r}$ ranged -0.117 to $-0.031, p<0.05$ ) and social support and all its three dimensions (i.e., objective support, subjective support, support utilization) ( $\mathrm{r}$ ranged -0.089 to $-0.037, p<0.01)$. Additionally, depression significantly negatively correlated with positive coping $(\mathrm{r}=-0.102, p<$ $0.01)$ and significantly positively correlated with negative coping $(\mathrm{r}=0.167, p<0.01)$. Similarly, anxiety significantly negatively correlated with family functioning and all five dimensions(i.e., adaptation, partnership, growth, affection, resolve) ( $\mathrm{r}$ ranged -0.264 to $-0.122, p<0.01$ ) and social support and all its three dimensions(i.e., objective support, subjective support, support utilization) (r ranged -0.17 to $-0.102, p<0.01)$. Also, anxiety significantly negatively correlated with positive coping $(\mathrm{r}=-$ $0.308, p<0.01)$ and significantly positively correlated with negative coping $(\mathrm{r}=0.245, p<0.01)$.

The results of the hierarchical regression of depression and anxiety symptoms are presented in Tables 4 and 5 . After adjusting demographic variables, negative coping was positively associated with depression $(\beta=0.226, p<$ 0.001 ). A 0.226 -unit rise in depression was associated with each unit increase in negative coping style (Table 4). 
Table 1 Demographic characteristics of the study population

\begin{tabular}{l} 
Variables \\
\hline Gender \\
Fale \\
Age \\
17-20 \\
21-25 \\
Grade \\
1st \\
2nd \\
3rd \\
Race/Ethnicity \\
Han nationality \\
Minority ethic group \\
Place of Residence \\
Urban \\
Rural \\
Housing \\
Alone \\
In student residence facility \\
with friends \\
With family
\end{tabular}

\section{Only child in the family}

Yes

No

\section{Family characteristics}

Core family (families consisting of parents and children)

Multi-generational family

Single parent family

Remarried family

\section{Household income per month}

$<$ RMB 5000

RMB 5000-10,000

$>$ RMB 10000

\section{Paternal education}

Illiteracy

Primary school

Secondary school

College and above

Maternal education

Illiteracy

Primary school

Secondary school

College and above

Paternal occupation ${ }^{\mathrm{a}}$
$N(\%)$

603(29.3)

1454(70.7)

835(40.6)

1222(59.4)

564(27.4)

$577(28.1)$

916(44.5)

1926(93.6)

$131(6.4)$

922(44.8)

1135(55.2)

134(6.5)

1201(58.4)

207(10.1)

515(25)

715(34.8)

1342(65.2)

1104(53.7)

690(33.5)

175(8.5)

$88(4.3)$

$1241(60.3)$

652(31.7)

164(8)

204(9.9)

642(31.2)

1080(52.5)

129(6.3)

266(12.9)

$787(38.3)$

910(44.2)

94(4.6)
Table 1 Demographic characteristics of the study population (Continued)

\begin{tabular}{ll}
\hline Variables & $\mathrm{N}(\%)$ \\
\hline Manual workers & $1688(82.1)$ \\
Mental workers & $367(17.8)$
\end{tabular}

\section{Maternal occupation ${ }^{a}$}

Manual workers

1557(75.7)

Mental workers

$500(24.3)$

Paternal health condition

Well

690(33.5)

Fare

1092(53.1)

Poor

275(13.4)

Maternal health condition

Well

653(31.7)

Fare

1037(50.4)

Poor

$367(17.8)$

Parents' way of raising you

Democracy

$1244(60.5)$

Authoritarian

$372(18.1)$

Laissez-faire

$441(21.4)$

Parents' care about you

Care

1473(71.6)

General

489(23.8)

Don't care

95(4.6)

Financial burden during the study

Big

658(32)

Genaral

1109(53.9)

Small

290(14.1)

Expectations of parents (or family members)

Big

1209(58.8)

Genaral 762(37)

Small

$86(4.2)$

Physical exercise

Never or rarely 575(28)

Occasional 1198(58.2)

Regular (at least 3 times a week, not less than $30 \mathrm{~min} \quad$ 284(13.8) each time)

1118(84.4)

$864(42)$

$75(3.6)$

Sleep quality

Well

$880(42.8)$

999(48.6)

178(8.7)

Study-induced stress

Large

$571(27.8)$ 
Table 1 Demographic characteristics of the study population (Continued)

\begin{tabular}{ll}
\hline Variables & $\mathrm{N}(\%)$ \\
\hline General & $1285(62.5)$ \\
Small & $200(9.7)$
\end{tabular}

Employment pressure

Large

976(47.4)

General

918(44.6)

Small

163(7.9)

Self-conceived character

Introvert

549(26.7)

Neutral

1070(52)

Extrovert

$437(21.2)$

Having chronic disease

No

1954(95)

Yes

$101(4.9)$

Satisfaction of specialty

Satisfied

809(39.3)

General

1123(54.6)

Dissatisfied

125(6.1)

Relationship with lovers

Harmony

582(28.3)

General

$333(16.2)$

Bad

$50(2.4)$

Not in love

1092(53.1)

Relationship with classmates or friends

Harmony

1350(65.6)

General

669(32.5)

Bad

$38(1.8)$

a Occupation: manual workers: workers/farmers/unemployment/commercial service providers/individual businesses/soldier; mental workers: teachers/ medical staff/cadres/S\&T workers

Table 5 indicates that three independent variable blocks significantly predicted anxiety symptoms: family function $\left(R^{2} \quad\right.$ change $\left.=0.026, \quad p<0.001\right)$, social support $\left(R^{2}\right.$ change $=0.002, \quad p<0.05), \quad$ positive $\operatorname{coping}\left(\mathbb{R}^{2}\right.$ change $=$ $0.018, p<0.001)$ and negative coping $\left(R^{2}\right.$ change $=0.035, p<$ 0.001). After adjusting demographic variables, negative coping positively associated with anxiety $(\beta=0.227, p<$ 0.001 ), while family function, social support and positive coping were negatively correlated to it $(\beta=-0.609, p<$ $0.001,-0.047, p<0.05$ and $-0.151, p<0.001$, respectively).

\section{Discussion}

The results of this study revealed a high prevalence of depression (57.5\%) among Chinese medical students from Chongqing Medical and Pharmaceutical College. Several previous studies have demonstrated similar high depression rates among medical students [48-50]. Fawzy et al. [14] reported an even higher rate (65\%). On the contrary, many other previous studies demonstrated lower rates of depression ranging from 15 to $24 \%$ in USA [51], 30.6\% in Cameroon [52], 29.5\% in Turkey [53], 37.2\% in Malaysia [54]. Also, the prevalence of depression of our sample (57.5\%) was much higher than the global prevalence $(28.0 \%)$ estimated by a metaanalysis of 62,728 medical students and 1845 nonmedical students pooled across 77 studies [55] and aggregate prevalence $(11.0 \%)$ estimated by a meta-analysis of 10,147 medical students in Asia [56]. According to our results, the overall anxiety symptom prevalence in our sample was $30.8 \%$, which was lower than that of another group of Chinese medical students $(47.3 \%)$ whose anxiety was measured by the same scale [5]. Also, the prevalence of anxiety of our sample (30.8\%) was similar to the global prevalence $(33.8 \%)$ estimated by a metaanalysis of 40,348 medical students across 69 studies [57]. Numerous studies showed that the prevalence of anxiety among medical students was $43.7 \%$ in Pakistan [8], 29.4\% in Israel [6], 44\% in Malaysia [7]. Additionally, we found that depression and anxiety were significantly positively correlated with each other. This finding is supported by other studies which shown that people with high anxiety were more likely to become more easily depressed [58] and major depressive disorder has high comorbidity with numerous anxiety disorders in general population [3].

In this study, we observed that older students $(\geq 20$ years) experienced higher levels of depression and anxiety. In accordance, Shamsuddin et al. [54] suggested that students in the older age group ( $\geq 20$ years) had higher depression and anxiety scores. Bostanci et al. [59] also reported higher scores of depression among senior Turkish students compared to the freshmen. We also reported higher scores of depression and anxiety among students in the third grade compared to those in the first and second grade.

This might suggest a decrease of psychological health in medical students. These findings were similar to the previous studies. Iqbal et al. [48] reported that fifth semester students had higher depression and anxiety scores than second and forth semester students. Baldassin et al. [60] found that Brazilian medical students in the internship period(5th and 6th years) exhibited higher depression levels in comparison to students both in the basic(1st and 2nd years) and intermediate(3rd and 4th years) periods. Chongqing Medical and Pharmaceutical College is a three-year medical education college in China which mainly trains doctors at the grassroots level. Grades 1 and 2 students learn the courses of medicine, and Grade 3 students enter clinical practice. Depression and anxiety may be more common among students in the third grade as a result of excessive workload of both paraclinical and clinical subjects, increasing 


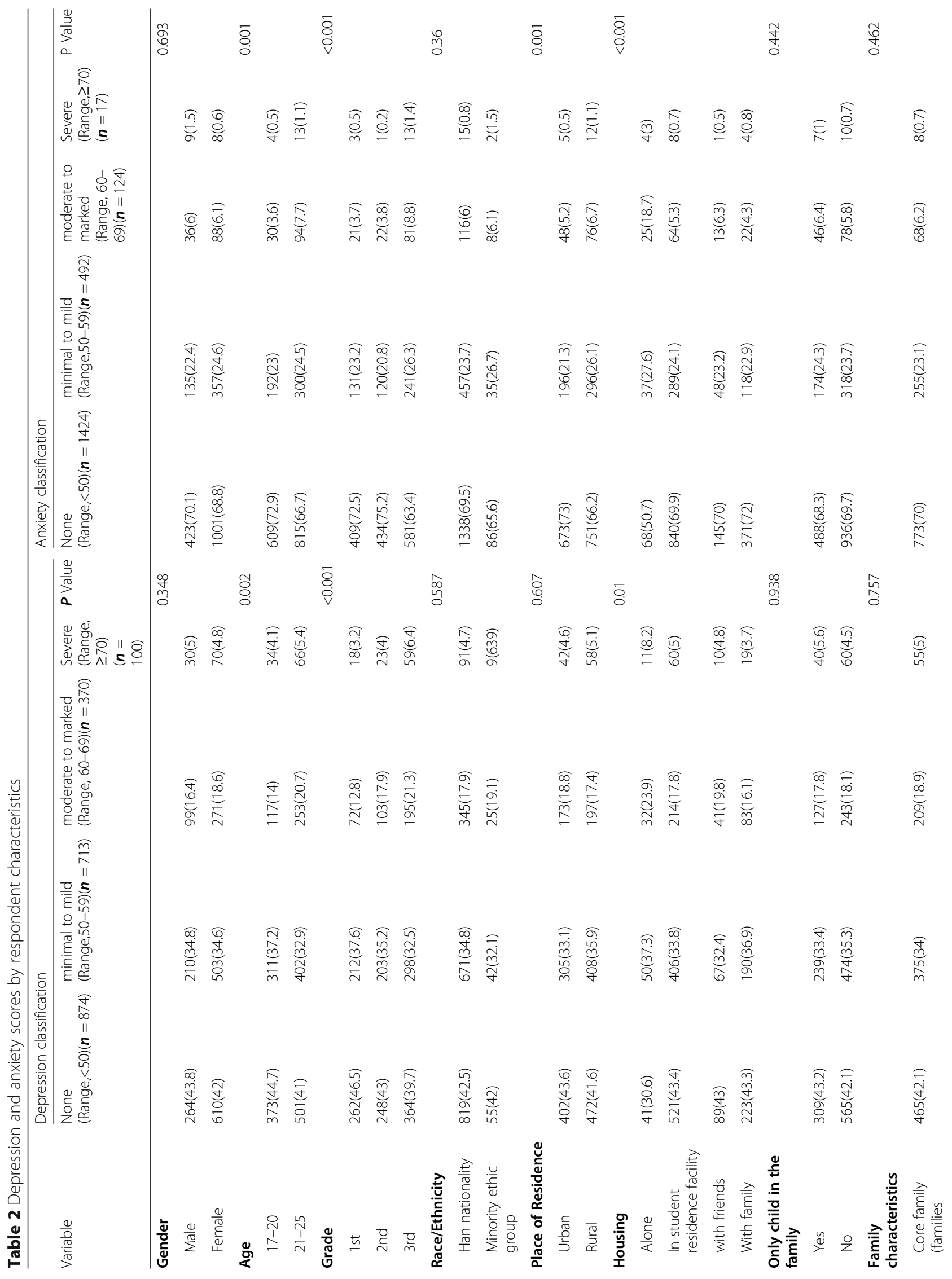




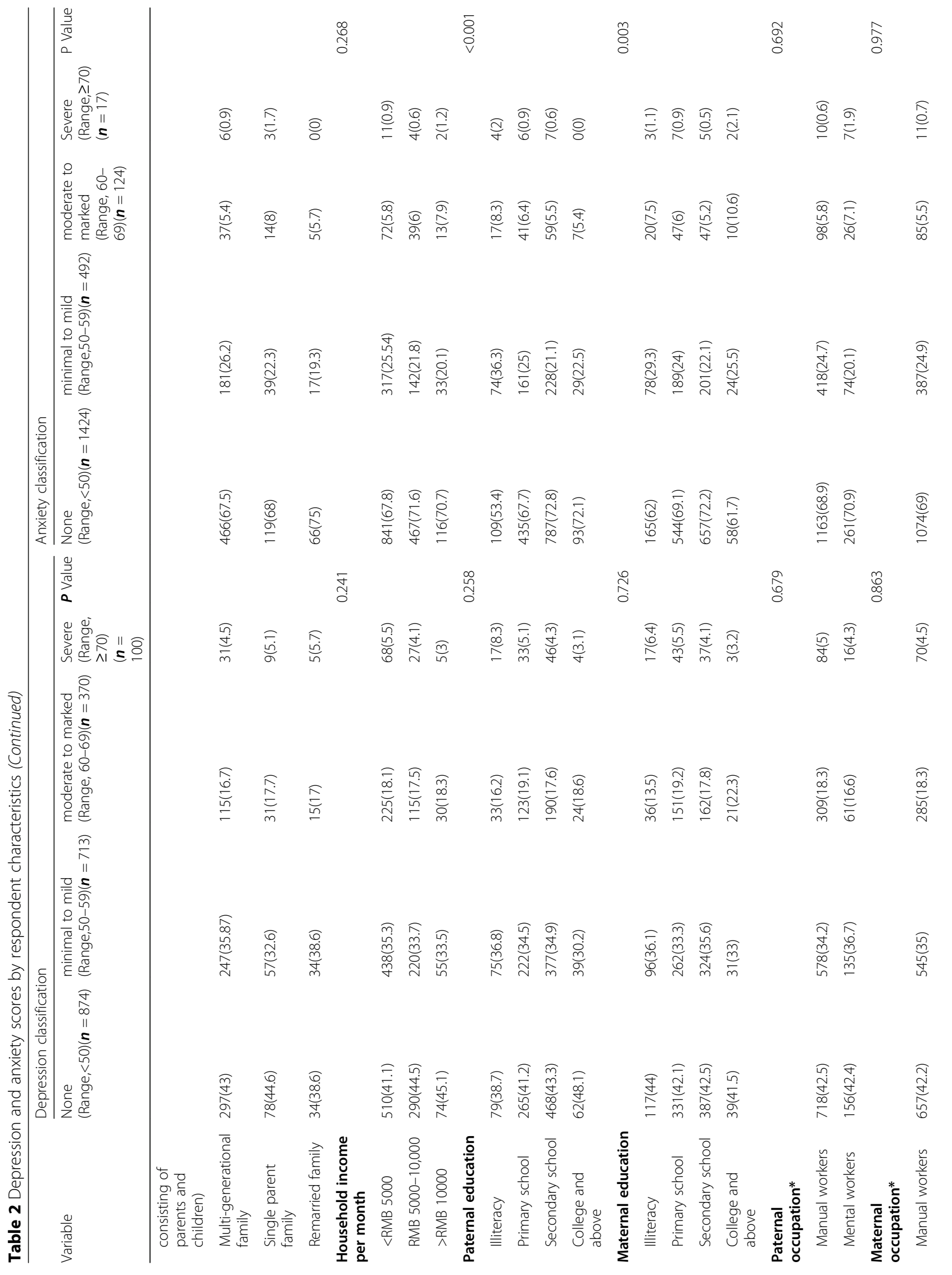




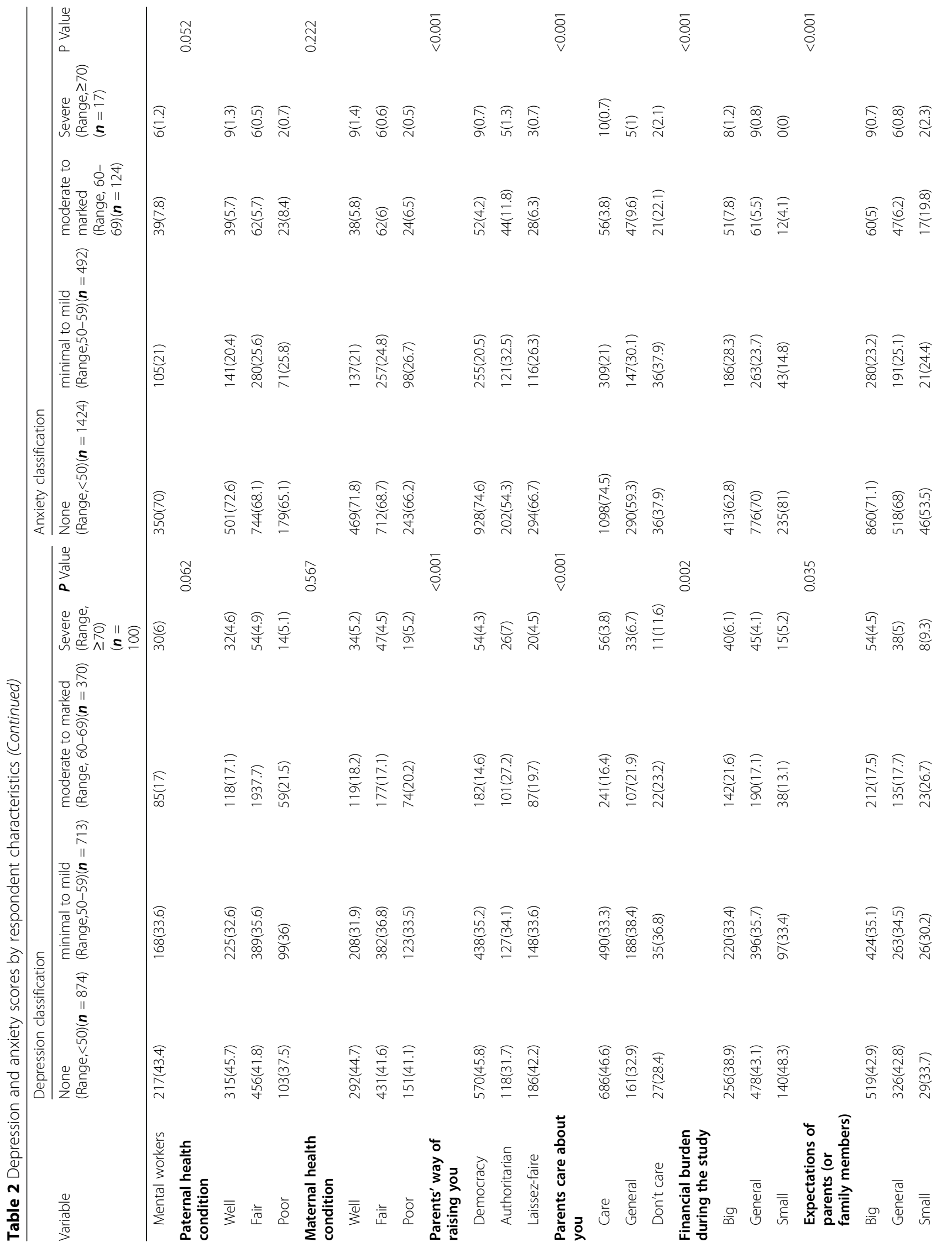




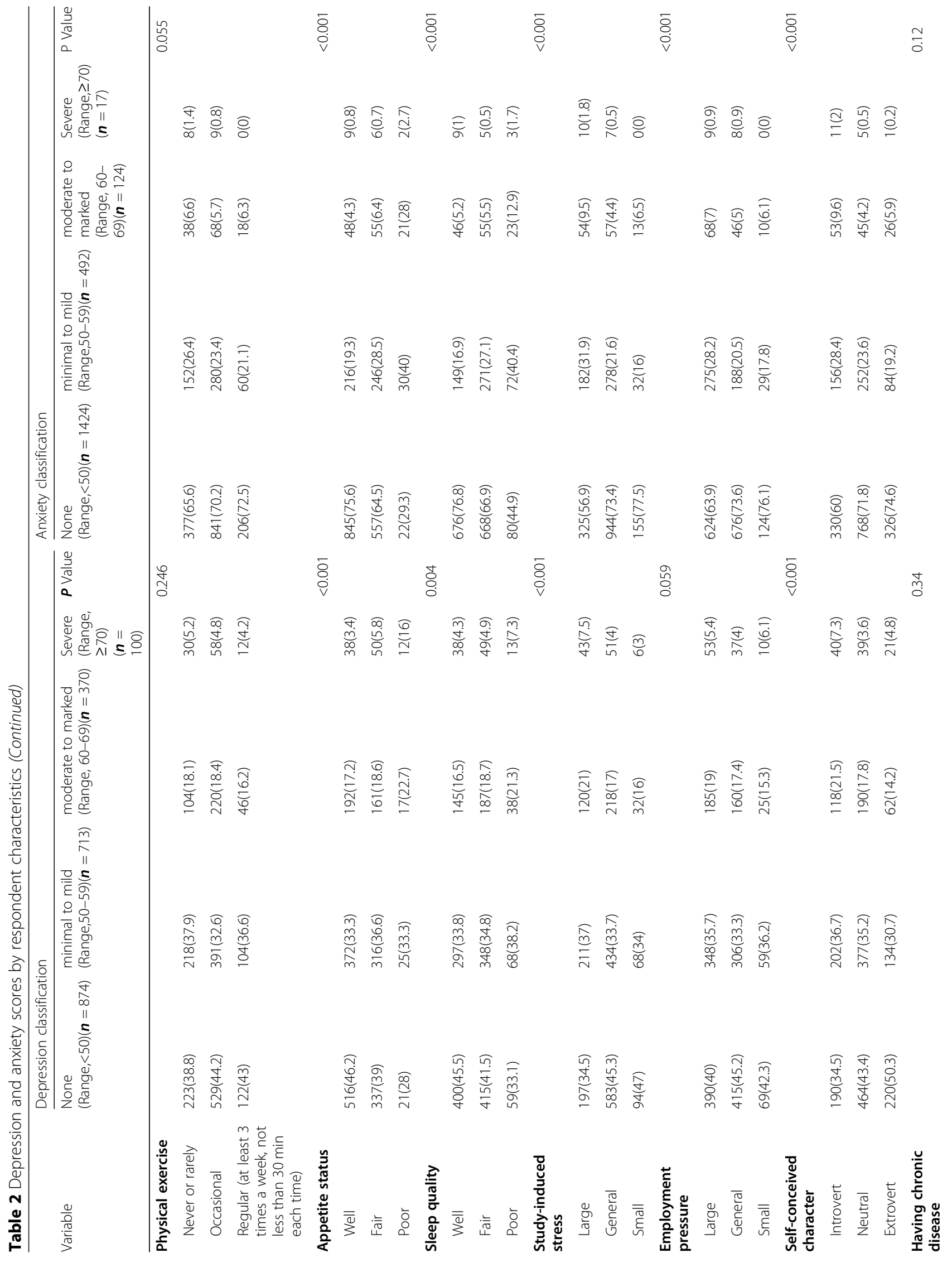




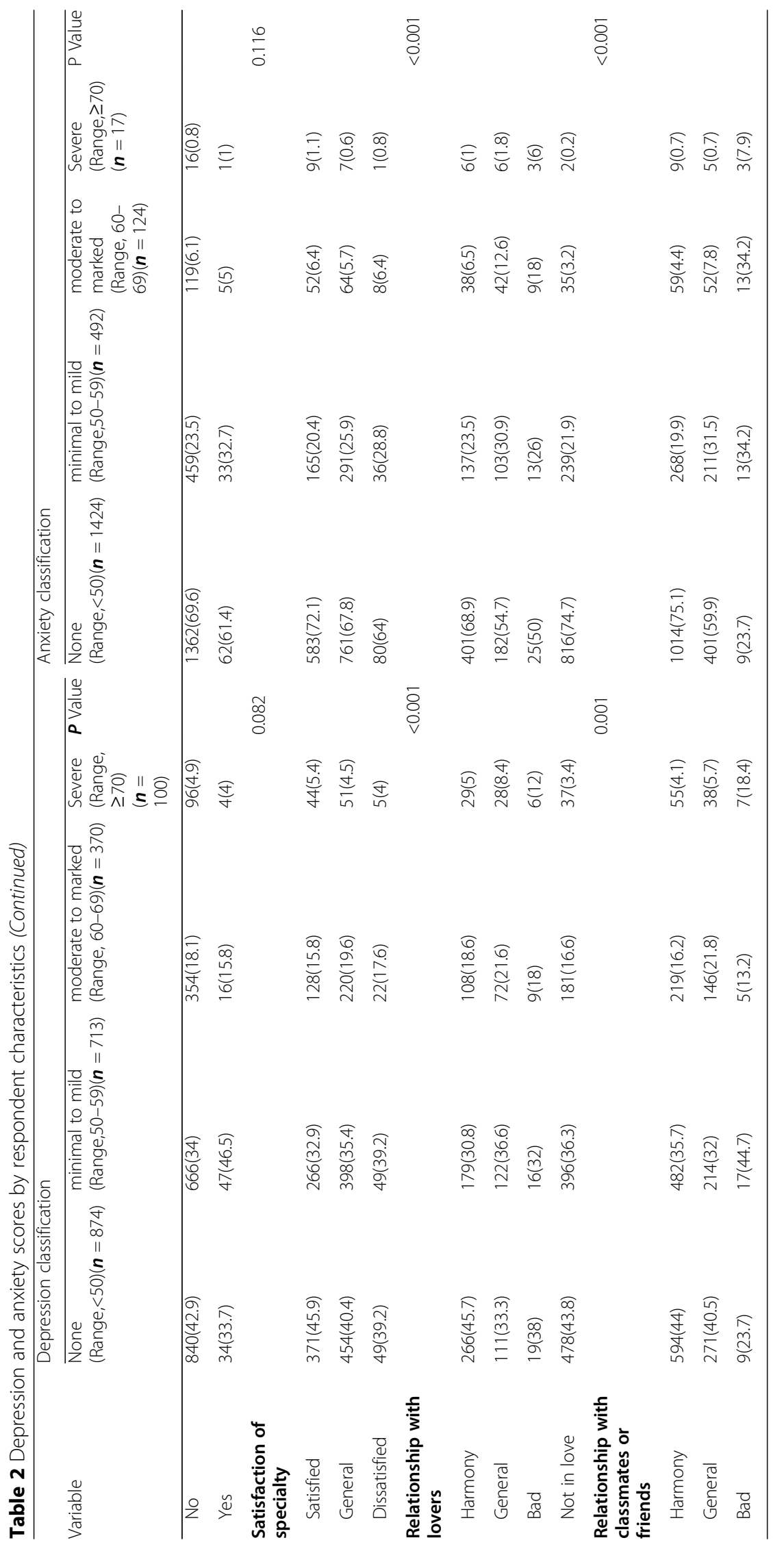




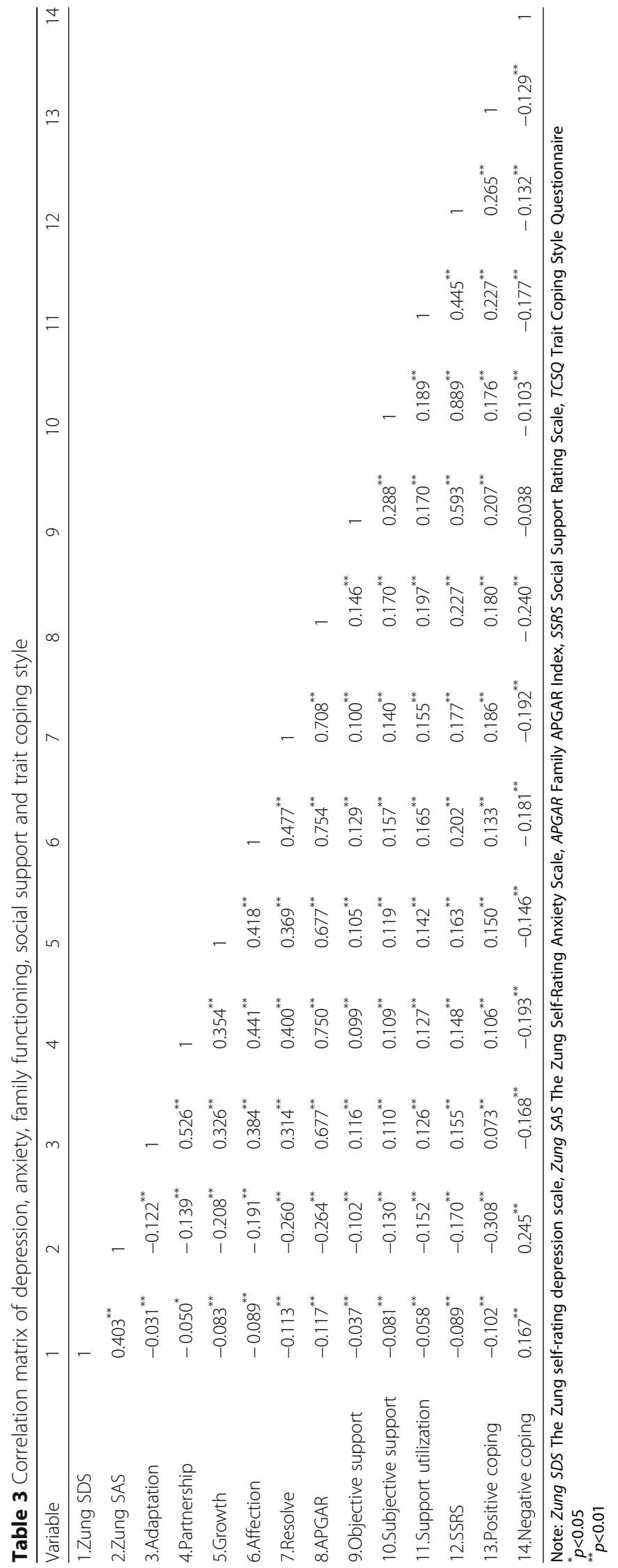


Table 4 Hierarchical linear regression analysis of independent factors correlated to depression symptoms

\begin{tabular}{|c|c|c|c|c|c|}
\hline \multirow{2}{*}{$\frac{\text { Variables }}{\text { Model } 1}$} & \multirow[t]{2}{*}{ Model 1( $\beta)$} & \multirow[t]{2}{*}{ Model 2( $\beta)$} & \multirow[t]{2}{*}{ Model 3( $\beta)$} & \multicolumn{2}{|l|}{ Model $4(\beta)$} \\
\hline & & & & & \\
\hline Gender:Male (ref:female) & -0.446 & -0.452 & -0.43 & -0.469 & -0.006 \\
\hline Age & 0.108 & 0.12 & 0.123 & 0.119 & 0.129 \\
\hline Grade & $0.973^{* *}$ & $1.02^{* *}$ & $1.019^{* *}$ & $1.018^{* *}$ & $0.98^{* *}$ \\
\hline Race/Ethnicity:Han nationality (ref: Minority ethic group) & 0.176 & 0.15 & 0.125 & 0.146 & 0.068 \\
\hline Place of Residence:Urban (ref:rural) & 0.411 & 0.46 & 0.429 & 0.425 & 0.262 \\
\hline Housing: In student residence facility (ref:alone) & -1.18 & -1.2 & -1.182 & -1.159 & -1.263 \\
\hline Housing:with friends (ref:alone) & $-2.237^{*}$ & -2.179 & -2.124 & -2.087 & -2.164 \\
\hline Housing:with family (ref:alone) & -1.487 & -1.498 & -1.464 & -1.448 & -1.572 \\
\hline Only child in the family: Yes (ref:no) & 0.064 & 0.072 & 0.019 & 0.028 & 0.025 \\
\hline Family characteristics: Multi-generational family (ref:core family) & -0.665 & -0.644 & -0.653 & -0.643 & -0.682 \\
\hline Family characteristics: Single parent family (ref:core family) & -1.035 & -1.041 & -1.054 & -1.075 & -0.923 \\
\hline Family characteristics: Remarried family (ref:core family) & -0.217 & -0.22 & -0.212 & -0.206 & -0.164 \\
\hline Household income per month: RMB 5000-10,000(ref:<RMB 5000) & $-1.266^{*}$ & $-1.274^{*}$ & $-1.284^{*}$ & $-1.299^{*}$ & $-1.232^{*}$ \\
\hline Household income per month:>RMB 10000(ref:<RMB 5000) & -0.846 & -0.937 & -0.906 & -0.9 & -1.036 \\
\hline Paternal education: Primary school (ref:illiteracy) & -0.204 & -0.242 & -0.281 & -0.299 & -0.132 \\
\hline Paternal education: Secondary school (refilliteracy) & -0.653 & -0.664 & -0.698 & -0.709 & -0.382 \\
\hline Paternal education: College and above (refilliteracy) & -0.396 & -0.342 & -0.367 & -0.31 & -0.135 \\
\hline Maternal education: Primary school (ref:illiteracy) & $1.509^{*}$ & $1.492^{*}$ & $1.494^{*}$ & $1.485^{*}$ & $1.526^{*}$ \\
\hline Maternal education: Secondary school (refilliteracy) & 1.097 & 1.127 & 1.136 & 1.123 & 1.23 \\
\hline Maternal education: College and above (ref:illiteracy) & 2.076 & 2.131 & 2.158 & 2.151 & 1.841 \\
\hline Paternal occupation: Mental workers (ref: Manual workers) & -0.455 & -0.49 & -0.494 & -0.466 & -0.588 \\
\hline Maternal occupation: Mental workers (ref: Manual workers) & 0.672 & 0.642 & 0.638 & 0.654 & 0.577 \\
\hline Paternal health condition & 0.218 & 0.216 & 0.224 & 0.248 & 0.17 \\
\hline Maternal health condition & -0.348 & -0.378 & -0.395 & -0.389 & -0.471 \\
\hline Parents' way of raising you: Authoritarian (ref:democracy) & $2.394^{* *}$ & $2.243^{* *}$ & $2.212^{* *}$ & $2.213^{* *}$ & $2.155^{* *}$ \\
\hline Parents' way of raising you: Laissez-faire (ref:democracy) & 0.18 & 0.067 & 0.037 & 0.064 & 0.012 \\
\hline Parents care about you & $1.498^{* *}$ & $1.348^{* *}$ & $1.331^{* *}$ & $1.34^{* *}$ & $1.355^{* *}$ \\
\hline Financial burden during the study & -0.368 & -0.341 & -0.333 & -0.322 & -0.378 \\
\hline Expectations of parents (or family members) & 0.091 & 0.074 & 0.074 & 0.065 & 0.099 \\
\hline Physical exercise & 0.187 & 0.216 & 0.238 & 0.227 & 0.379 \\
\hline Appetite status & $1.032^{*}$ & $1.006^{*}$ & $1.003^{*}$ & $0.991^{*}$ & $0.99^{*}$ \\
\hline Sleep quality & 0.383 & 0.365 & 0.336 & 0.319 & 0.309 \\
\hline Study-induced stress & $-1.173^{* *}$ & $-1.146^{* *}$ & $-1.144^{* *}$ & $-1.161^{* *}$ & $-0.887^{*}$ \\
\hline Employment pressure & -0.093 & -0.063 & -0.055 & -0.045 & 0.167 \\
\hline Self-conceived character: Neutral (ref:introvert) & $-1.678^{* *}$ & $-1.613^{* *}$ & $-1.603^{* *}$ & $-1.576^{* *}$ & $-1.439^{* *}$ \\
\hline Self-conceived character: Extrovert (ref:introvert) & $-1.968^{* *}$ & $-1.9^{* *}$ & $-1.859^{* *}$ & $-1.795^{* *}$ & $-1.725^{* *}$ \\
\hline Having chronic disease: Yes (ref:no) & 1.153 & 1.158 & 1.181 & 1.18 & 1.074 \\
\hline Satisfaction of specialty & 0.32 & 0.263 & 0.241 & 0.243 & 0.187 \\
\hline Relationship with lovers & 0.299 & 0.297 & 0.334 & 0.305 & $0.382^{*}$ \\
\hline Relationship with classmates or friends & 0.754 & 0.656 & 0.614 & 0.566 & 0.564 \\
\hline \multicolumn{6}{|l|}{ Model 2} \\
\hline Family function & & -0.201 & -0.186 & -0.179 & -0.049 \\
\hline
\end{tabular}

Model 3 
Table 4 Hierarchical linear regression analysis of independent factors correlated to depression symptoms (Continued)

\begin{tabular}{|c|c|c|c|c|c|}
\hline Variables & Model 1( $\beta)$ & Model 2( $\beta)$ & Model $3(\beta)$ & Model 4( $\beta)$ & \\
\hline Social support & & & -0.034 & -0.026 & -0.028 \\
\hline \multicolumn{6}{|l|}{ Model 4} \\
\hline Positive coping & & & & -0.033 & \\
\hline Negative coping & & & & & $0.226^{* *}$ \\
\hline$F$ & $4.123^{* *}$ & $4.116^{* *}$ & $4.042^{* *}$ & $3.973^{* *}$ & $5.064^{* *}$ \\
\hline R2 & 0.076 & 0.077 & 0.078 & 0.078 & 0.098 \\
\hline$\Delta R 2$ & 0.076 & 0.002 & 0 & 0 & 0.02 \\
\hline
\end{tabular}

tension between doctors and patients in recent years in China and worry about not attaining their goal of being a doctor. In contrast, some studies identified that preclinical students exhibited higher levels of depression and anxiety compared to students in higher years of study $[14,61]$ and some identified no difference in depression and anxiety prevalence according to students' year of study [3]. These conflicting findings may be due to differences in study populations. Nevertheless, depression and anxiety experienced by medical students could be a predisposing factor to burnout during residency or postgraduate training [62].

In our study, we reported that more depression and anxiety symptoms were exhibited among students with significant financial burden, high level of academic stress and poor sleep quality. Students with large employment pressure showed more anxiety symptoms. Previous studies have suggested that academic pressure, workload, sleep deprivation and financial concerns may have an adverse effect on students' mental health [3, 14, 63, 64]. Wege et al. [18] indicated that expected financial hardships were significantly associated with mental health disorders and psychosomatic symptoms. Association between worrying about the future with anxiety scores had been reported [65]. Getting into medical school required to the students changing their lifestyle [3]. One of these changes is living away from their families and friends. In this case housing accommodations can impact the medical students' mental health. Our hypothesis that students who live alone have higher levels of depression and anxiety has been confirmed. Furthermore we confirmed the hypotheses that students had bad relationship with their lovers or classmates or friends showed higher depression and anxiety scores, which was consistent with previous studies $[65,66]$.

Social support has been defined as "a social network's provision of psychological and material resources intended to benefit an individual's ability to cope with stress" by Cohen [67]. The negative relationship between social support and psychological symptoms (depression, anxiety) supports the findings of previous studies [47,
58]. It is generally believed that positive social support is an important aspect of psychological adjustment that could help buffer the pathogenic effects of stress [58, 68]. It was reported the lack of social support associated with reduced positive emotion and experience, and lessened psychological well-being of medical students [65, 69]. Kjeldstadli et al. [70] also indicated that medical students who perceived medical school as interfering less with their social and personal lives were psychologically more stable.

Family is an important source of support for Chinese medical students. Our study found a negative relationship between family function and psychological symptoms (depression, anxiety). This result was aligned with previous studies suggesting an association between family dysfunction and depressive symptoms [71]. Wickrama KA et al. [72] also reported that positive family functioning reduced mothers' depressive symptoms in Tsunamiaffected families. The emotional comforts of the family function may help to improve physical and psychological well-being of medical students.

Coping refers to the individual cognitive and behavioral strategies to master, reduce or tolerate the internal and external demands of stressful situations [25]. The term "coping styles" is applied to more consistent tendencies to cope in a particular way [73]. Coping styles are broadly grouped into positive coping (PC) and negative coping (NC) styles [74]. The results of this study indicated that positive coping was negatively related to psychological symptoms (depression, anxiety), while negative coping was positively related to them. The results of hierarchical regression also revealed that coping styles were the independent predictors of psychological symptoms. These findings were congruent with previous studies in China. Luo et al. reported that negative coping was positively correlated to psychological symptoms and positive coping was negatively correlated to them among Chinese nurse students [47]. However, one study in Brazil reported either $\mathrm{PC}$ or NC styles to be correlated to more depressive symptoms [75], and another study in the United States found null effect of coping styles on 


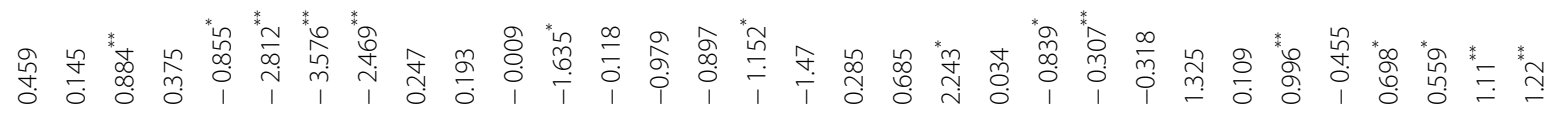

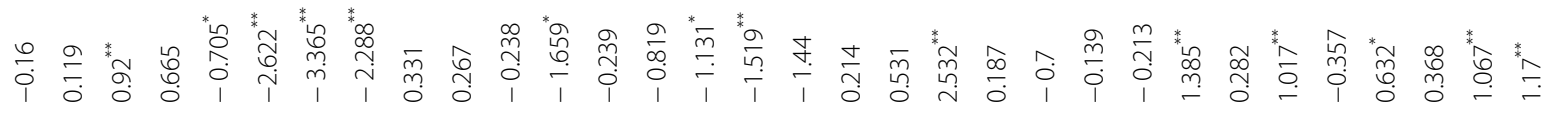

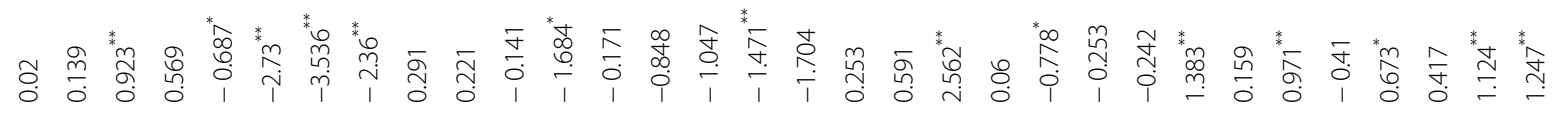

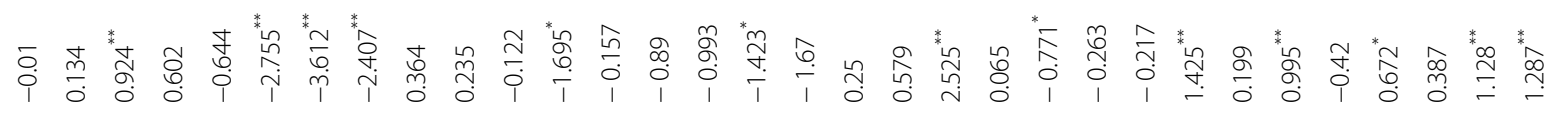

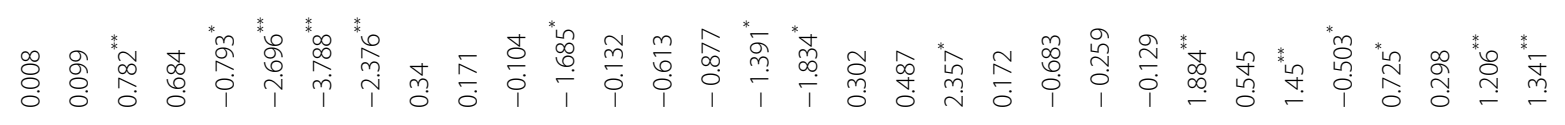
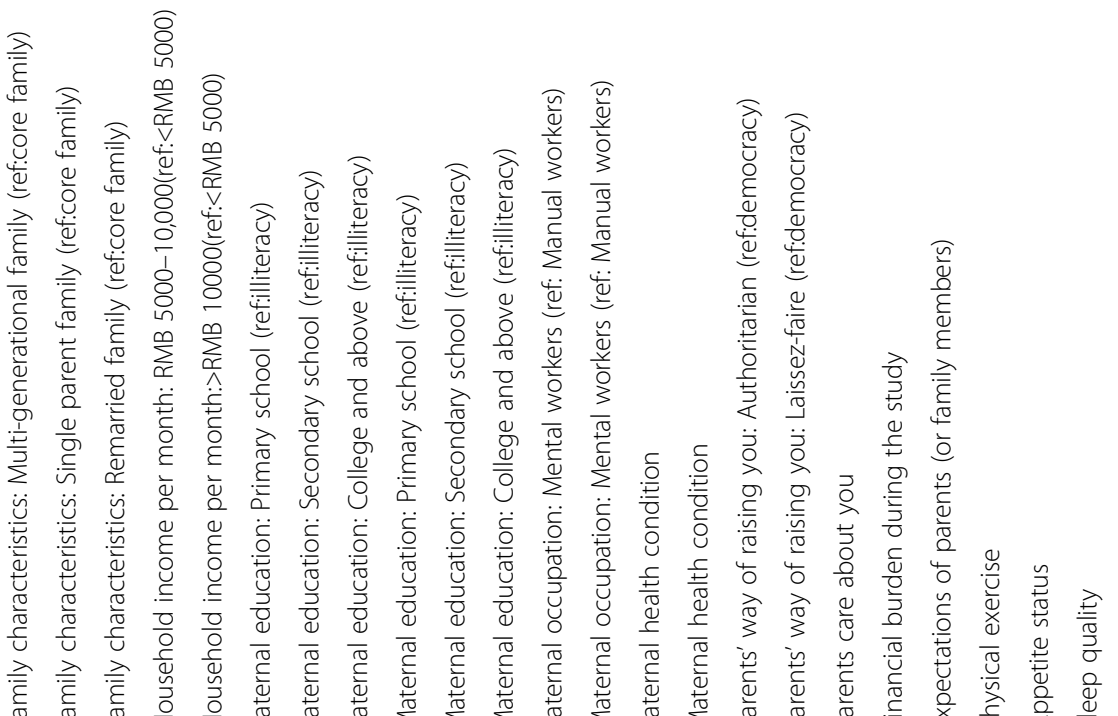


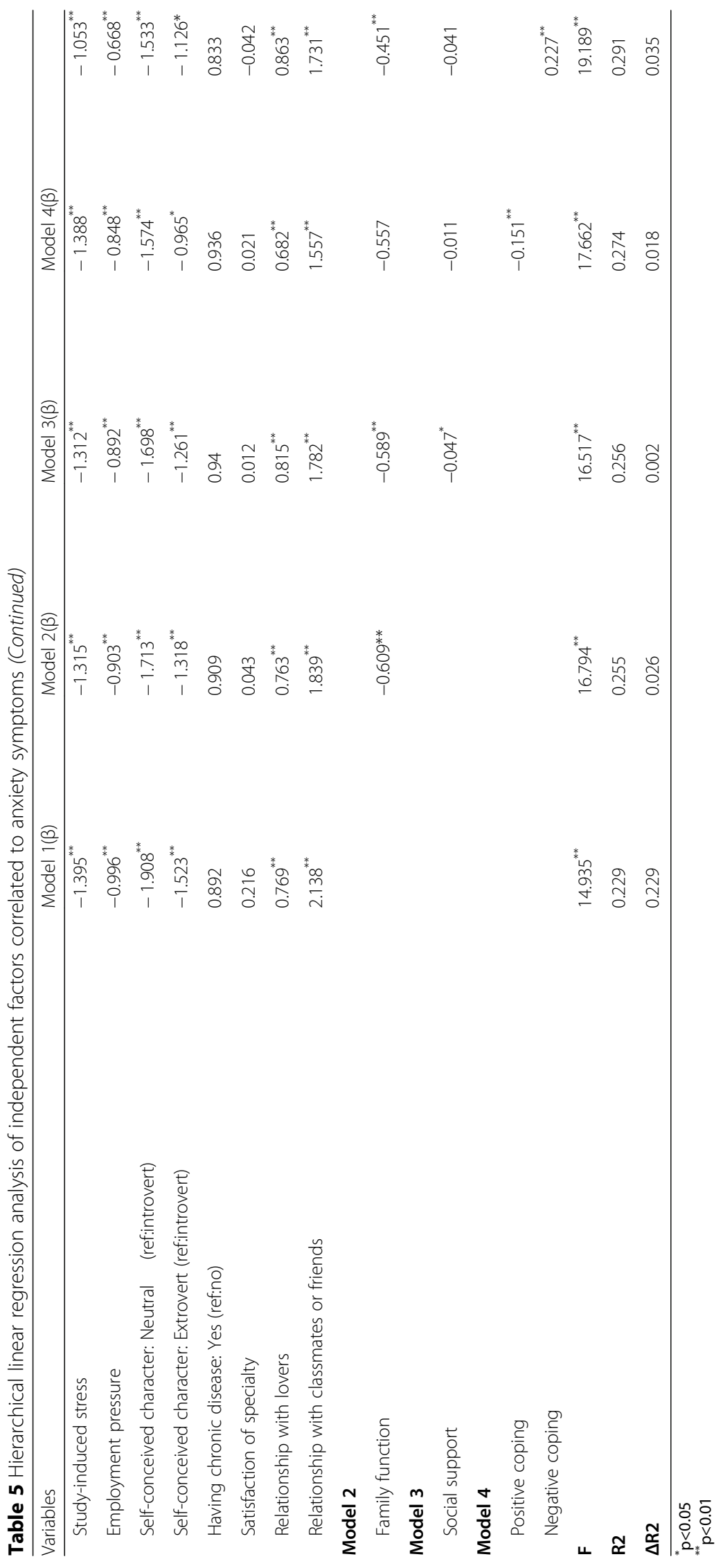


mental health [76]. These mixed findings may be due to different countries.

There are several limitations in the present study. First, the study design was cross-sectional, which precluding definitive conclusions regarding the direction of causality between social support, family functioning, coping styles and psychological morbidity. Further longitudinal studies are expected to explore the causalities. Second, the study population consisted only of medical students in one Chinese medical school and therefore may not be extended directly to other settings. Medical students from other universities will be investigated in our further research. Third, all questionnaires were selfreport and therefore the inherent limitations of selfreported measures should be noted. Fourth, all medical students from Chongqing Medical and Pharmaceutical College in China were eligible to participate in the study and there were no exclusion criteria. This may lead to a self-selection bias, as medical students with depression or anxiety symptoms may be less motivated to completed the questionnaires, or on the other hand, they may be more likely to participate since the topic is relevant to them. Finally, the effect of psychological mechanism on depression and anxiety of Chinese medical students has not been studied in this study. Studies have found that certain psychological mechanisms are related to depression and anxiety. Studies showed that depressive symptoms and rumination in individuals are usually highly correlated. In one study, individuals who had more ruminative responses about the 1989 Loma Prieta Earthquake were more likely to have prolonged high levels of depression than those who did not develop these thought patterns [77]. In another study, rumination was associated with longer and more severe depression after experiencing stress [78]. This aspect can be further studied in our future research.

\section{Conclusions}

The present study reported a relatively high prevalence of depression and anxiety symptoms in a sample of Chinese medical students. Multiple factors were related to depression and anxiety symptoms. Supportive social relationships, positive family function and positive coping style may play an important role in reducing the stresses and improving their mental well-being. These results are important for both students and academic staffs. By broadening social relationships and adopting more positive coping and less negative coping skills, depression and anxiety symptoms may be prevented or at least diminished among medical students. In addition, academic staffs should take measures and interventions to reduce depression and anxiety among medical students and to provide educational counseling and psychological support for students to cope with these problems.

\section{Abbreviations}

SDS: Self-rating depression scale; SAS: 'Self-rating anxiety scale; APGAR: adaptation, partnership, growth, affection, resolve; SSRS: Social support rating scale; TCSQ: Trait Coping Style Questionnaire

\section{Acknowledgements \\ The authors sincerely thank all the investigators and students who participated in the survey.}

\section{Authors' contributions}

RS and $Y Y$ conceived and designed the study. PH, BL, LT and LX undertook the data collection and analysis. $Y Y, Y H$ and LK drafted the manuscript. RS and $\mathrm{PH}$ reviewed the manuscript. The authors read and approved the final manuscript.

\section{Funding}

This work was supported by Chongqing Education Commission Humanities and Social Sciences Research Project(17SKG259), Chongqing Higher Vocational and Technical Education Research Association (GY174014) and Chongqing Education Science Planning Office(2016-GX-073). The funding bodies did not play any roles in the design of the study, data collection, analysis, data interpretation, or writing of the manuscript.

\section{Availability of data and materials}

The detasets used analysed during the current study are available from the corresponding author on reasonable request.

\section{Ethics approval and consent to participate}

The study was approved by the Ethical Committee of Chongqing Medical and Pharmaceutical College and written informed consent was required from all participants. Participation was voluntary and students were informed about the purpose of the study. Confidentiality was assured and questionnaires were submitted anonymously.

\section{Consent for publication}

Not applicable.

\section{Competing interests}

The authors declare that they have no competing interests.

\section{Author details}

'School of Clinical Medicine, Chongqing Medical and Pharmaceutical College, No. 82, Daxuecheng Rd, Shapingba Dist, Chongqing 401331, China. ${ }^{2}$ Chongqing Engineering Research Center of Pharmaceutical Sciences, Chongqing 401331, China. ${ }^{3}$ Department of Pharmacology, Chongqing Medical and Pharmaceutical College, No. 82, Daxuecheng Rd, Shapingba Dist, Chongqing 401331, China. ${ }^{4}$ School of Basic Medical Sciences, Chongqing Medical and Pharmaceutical College, No. 82, Daxuecheng Rd, Shapingba Dist, Chongqing 401331, China. ${ }^{5}$ Key Laboratory of Clinical Laboratory Diagnostics (Ministry of Education), College of Laboratory Medicin, Chongqing Medical University, No.1 Yixueyuan Road, Yuzhong District, Chongqing 400016, China. '5Chool of Basic Medical Sciences, Chongqing Medical University, No.1 Yixueyuan Road, Yuzhong District, Chongqing 400016, China.

Received: 3 September 2019 Accepted: 3 April 2020

Published online: 22 April 2020

\section{References}

1. Ibrahim AK, Kelly SJ, Adams CE, Glazebrook C. A systematic review of studies of depression prevalence in university students. J Psychiatr Res. 2013:47(3):391-400.

2. Naja WJ, Kansoun AH, Haddad RS. Prevalence of depression in medical students at the Lebanese University and exploring its correlation with Facebook relevance: a questionnaire study. JMIR Res Protoc. 2016;5(2):e96.

3. Brenneisen Mayer F, Souza Santos I, Silveira PS, Itaqui Lopes MH, de Souza $A R$, Campos EP, et al. Factors associated to depression and anxiety in medical students: a multicenter study. BMC Med Educ. 2016;16(1):282.

4. lorga M, Dondas C, Zugun-Eloae C. Depressed as freshmen, stressed as seniors: the relationship between depression, perceived stress and academic results among medical students. Behav Sci (Basel). 2018;8(8):70. 
5. Shi M, Liu L, Wang ZY, Wang L. The mediating role of resilience in the relationship between big five personality and anxiety among Chinese medical students: a cross-sectional study. PLoS One. 2015;10(3):e0119916.

6. Lupo MK, Strous RD. Religiosity, anxiety and depression among Israeli medical students. Isr Med Assoc J. 2011;13(10):613-8.

7. Yusoff MS, Abdul Rahim AF, Baba AA, Ismail SB, Mat Pa MN, Esa AR. Prevalence and associated factors of stress, anxiety and depression among prospective medical students. Asian J Psychiatr. 2013;6(2):128-33.

8. Rab F, Mamdou R, Nasir S. Rates of depression and anxiety among female medical students in Pakistan. East Mediterr Health J. 2008;14(1):126-33.

9. Moutinho IL, Maddalena NC, Roland RK, Lucchetti AL, Tibirica SH, Ezequiel OD, et al. Depression, stress and anxiety in medical students: a crosssectional comparison between students from different semesters. Rev Assoc Med Bras (1992). 2017;63(1):21-8.

10. Haldorsen $H$, Bak NH, Dissing A, Petersson B. Stress and symptoms of depression among medical students at the University of Copenhagen. Scand J Public Health. 2014:42(1):89-95.

11. Bassols AM, Okabayashi LS, Silva AB, Carneiro BB, Feijo F, Guimaraes GC, et al. First- and last-year medical students: is there a difference in the prevalence and intensity of anxiety and depressive symptoms? Braz J Psychiatr. 2014;36(3):233-40.

12. Dyrbye LN, Thomas MR, Shanafelt TD. Systematic review of depression, anxiety, and other indicators of psychological distress among U.S. and Canadian medical students. Acad Med. 2006;81(4):354-73.

13. Nasioudis D, Palaiodimos L, Dagiasis M, Katsarou A, Ntouros E. Depression in military medicine cadets: a cross-sectional study. Mil Med Res. 2015;2:28.

14. Fawzy M, Hamed SA. Prevalence of psychological stress, depression and anxiety among medical students in Egypt. Psychiatry Res. 2017;255:186-94.

15. Azim SR, Baig M. Frequency and perceived causes of depression, anxiety and stress among medical students of a private medical institute in Karachi: a mixed method study. J Pak Med Assoc. 2019;69(6):840-5.

16. Rosenthal JM, Okie S. White coat, mood indigo--depression in medical school. N Engl J Med. 2005;353(11):1085-8.

17. Hojat M, Glaser K, Xu G, Veloski JJ, Christian EB. Gender comparisons of medical students' psychosocial profiles. Med Educ. 1999;33(5):342-9.

18. Wege N, Muth T, Li J, Angerer P. Mental health among currently enrolled medical students in Germany. Public Health. 2016;132:92-100.

19. Tyssen R, Vaglum P, Gronvold NT, Ekeberg O. Suicidal ideation among medical students and young physicians: a nationwide and prospective study of prevalence and predictors. J Affect Disord. 2001;64(1):69-79.

20. Midtgaard M, Ekeberg O, Vaglum P, Tyssen R. Mental health treatment needs for medical students: a national longitudinal study. Eur Psychiatry. 2008;23(7):505-11.

21. Stewart SM, Lam TH, Betson CL, Wong CM, Wong AM. A prospective analysis of stress and academic performance in the first two years of medical school. Med Educ. 1999;33(4):243-50.

22. Walkiewicz M, Tartas M, Majkowicz M, Budzinski W. Academic achievement, depression and anxiety during medical education predict the styles of success in a medical career: a 10-year longitudinal study. Med Teach. 2012;34(9):e611-9.

23. Zhang MWB, Lim RBC, Lee C, Ho RCM. Prevalence of internet addiction in medical students: a meta-analysis. Acad Psychiatry. 2018;42(1):88-93.

24. de La Rosa-Rojas G, Chang-Grozo S, Delgado-Flores L, Oliveros-Lijap L, Murillo-Perez D, Ortiz-Lozada R, et al. Level of stress and coping strategy in medical students compared with students of other careers. Gac Med Mex. 2015;151(4):443-9.

25. Folkman S, Moskowitz JT. Coping: pitfalls and promise. Annu Rev Psychol. 2004;55:745-74

26. Lau $Y$, Wang $Y$, Kwong DH, Wang Y. Are different coping styles mitigating perceived stress associated with depressive symptoms among pregnant women? Perspect Psychiatr Care. 2016;52(2):102-12.

27. Ding $Y$, Yang $Y$, Yang $X$, Zhang T, Qiu $X$, He $X$, et al. The mediating role of coping style in the relationship between psychological capital and burnout among Chinese nurses. PLoS One. 2015;10(4):e0122128.

28. Wu L, Farquhar J, Ma J, Vidyarthi AR. Understanding Singaporean medical students' stress and coping. Singapore Med J. 2018;59(4):172-6.

29. Zeng W, Chen R, Wang X, Zhang Q, Deng W. Prevalence of mental health problems among medical students in China: a meta-analysis. Medicine (Baltimore). 2019;98(18):e15337.

30. Mao Y, Zhang N, Liu J, Zhu B, He R, Wang X. A systematic review of depression and anxiety in medical students in China. BMC Med Educ. 2019; 19(1):327.
31. Cheng C, Liu X, Fan W, Bai X, Liu Z. Comprehensive rehabilitation training decreases cognitive impairment, anxiety, and depression in Poststroke patients: a randomized, controlled study. J Stroke Cerebrovasc Dis. 2018; 27(10):2613-22.

32. Liao Y, Knoesen NP, Deng Y, Tang J, Castle DJ, Bookun R, et al. Body dysmorphic disorder, social anxiety and depressive symptoms in Chinese medical students. Soc Psychiatry Psychiatr Epidemiol. 2010;45(10):963-71.

33. Zung WW, Gianturco JA. Personality dimension and the self-rating depression scale. J Clin Psychol. 1971;27(2):247-8.

34. Chen SB, Hu H, Gao YS, He HY, Jin DX, Zhang CQ. Prevalence of clinical anxiety, clinical depression and associated risk factors in chinese young and middle-aged patients with osteonecrosis of the femoral head. PLoS One. 2015:10(3):e0120234.

35. Leung KK, Lue BH, Lee MB, Tang LY. Screening of depression in patients with chronic medical diseases in a primary care setting. Fam Pract. 1998; 15(1):67-75.

36. Zung WW. A rating instrument for anxiety disorders. Psychosomatics. 1971; 12(6):371-9.

37. Gainotti G, Cianchetti C, Taramelli M, Tiacci C. The guided self-rating anxiety-depression scale for use in clinical psychopharmacology. Act Nerv Super (Praha). 1972:14(1):49-51.

38. Gao YQ, Pan BC, Sun W, Wu H, Wang JN, Wang L. Anxiety symptoms among Chinese nurses and the associated factors: a cross sectional study. BMC Psychiatry. 2012;12:141

39. Gong Y, Han T, Chen W, Dib HH, Yang G, Zhuang R, et al. Prevalence of anxiety and depressive symptoms and related risk factors among physicians in China: a cross-sectional study. PLoS One. 2014;9(7):e103242.

40. Ding Y, Qu J, Yu X, Wang S. The mediating effects of burnout on the relationship between anxiety symptoms and occupational stress among community healthcare workers in China: a cross-sectional study. PLoS One. 2014;9(9):e107130

41. Smilkstein G. The family APGAR: a proposal for a family function test and its use by physicians. J Fam Pract. 1978;6(6):1231-9.

42. Smilkstein G, Ashworth C, Montano D. Validity and reliability of the family APGAR as a test of family function. J Fam Pract. 1982;15(2):303-11.

43. Yu Y, Yang JP, Shiu CS, Simoni JM, Xiao S, Chen WT, et al. Psychometric testing of the Chinese version of the medical outcomes study social support survey among people living with HIV/AIDS in China. Appl Nurs Res. 2015;28(4):328-33.

44. Cheng Y, Liu C, Mao C, Qian J, Liu K, Ke G. Social support plays a role in depression in Parkinson's disease: a cross-section study in a Chinese cohort. Parkinsonism Relat Disord. 2008;14(1):43-5.

45. Xie RH, He G, Koszycki D, Walker M, Wen SW. Prenatal social support, postnatal social support, and postpartum depression. Ann Epidemiol. 2009; 19(9):637-43.

46. Ke X, Liu C, Li N. Social support and quality of life: a cross-sectional study on survivors eight months after the 2008 Wenchuan earthquake. BMC Public Health. 2010;10:573.

47. Luo $Y$, Wang H. Correlation research on psychological health impact on nursing students against stress, coping way and social support. Nurse Educ Today. 2009;29(1):5-8.

48. lqbal S, Gupta S, Venkatarao E. Stress, anxiety and depression among medical undergraduate students and their socio-demographic correlates. Indian J Med Res. 2015;141(3):354-7.

49. Al-Faris EA, Irfan F, Van der Vleuten CP, Naeem N, Alsalem A, Alamiri N, et al. The prevalence and correlates of depressive symptoms from an Arabian setting: a wake up call. Med Teach. 2012;34(Suppl 1):S32-6.

50. Honney K, Buszewicz M, Coppola W, Griffin M. Comparison of levels of depression in medical and non-medical students. Clin Teach. 2010;7(3):180-

51. Tjia J, Givens JL, Shea JA. Factors associated with undertreatment of medical student depression. J Am Coll Health. 2005;53(5):219-24.

52. Ngasa SN, Sama CB, Dzekem BS, Nforchu KN, Tindong M, Aroke D, et al. Prevalence and factors associated with depression among medical students in Cameroon: a cross-sectional study. BMC Psychiatry. 2017;17(1):216.

53. Baykan Z, Nacar M, Cetinkaya F. Depression, anxiety, and stress among lastyear students at Erciyes University medical school. Acad Psychiatry. 2012; 36(1):64-5.

54. Shamsuddin K, Fadzil F, Ismail WS, Shah SA, Omar K, Muhammad NA, et al. Correlates of depression, anxiety and stress among Malaysian university students. Asian J Psychiatr. 2013;6(4):318-23. 
55. Puthran R, Zhang MW, Tam WW, Ho RC. Prevalence of depression amongst medical students: a meta-analysis. Med Educ. 2016;50(4):456-68.

56. Cuttilan AN, Sayampanathan AA, Ho RC. Mental health issues amongst medical students in Asia: a systematic review [2000-2015]. Ann Transl Med. 2016:4(4):72.

57. Quek T, Tam WW, Tran BX, Zhang M, Zhang Z, Ho CS, et al. The global prevalence of anxiety among medical students: a meta-analysis. Int JEnviron Res Public Health. 2019;16(15):2735.

58. Xu J, Wei Y. Social support as a moderator of the relationship between anxiety and depression: an empirical study with adult survivors of Wenchuan earthquake. PLoS One. 2013:8(10):e79045.

59. Bostanci M, Ozdel O, Oguzhanoglu NK, Ozdel L, Ergin A, Ergin N, et al. Depressive symptomatology among university students in Denizli, Turkey: prevalence and sociodemographic correlates. Croat Med J. 2005;46(1):96-100.

60. Baldassin S, Alves TC, de Andrade AG, Nogueira Martins LA. The characteristics of depressive symptoms in medical students during medical education and training: a cross-sectional study. BMC Med Educ. 2008;8:60.

61. Bassols AM, Okabayashi LS, Silva AB, Carneiro BB, Feijo F, Guimaraes GC, et al. First- and last-year medical students: is there a difference in the prevalence and intensity of anxiety and depressive symptoms? Braz J Psychiatry. 2014;36(3):233-40.

62. Low ZX, Yeo KA, Sharma VK, Leung GK, McIntyre RS, Guerrero A, et al. Prevalence of burnout in medical and surgical residents: a meta-analysis.Int J Environ Res Public Health. 2019;16(9):1479.

63. Yusoff MS, Abdul Rahim AF, Baba AA, Ismail SB, Mat Pa MN, Esa AR. The impact of medical education on psychological health of students: a cohort study. Psychol Health Med. 2013;18(4):420-30.

64. Bernhardt V, Rothkotter HJ, Kasten E. Psychological stress in first year medical students in response to the dissection of a human corpse. GMS Z Med Ausbild. 2012;29(1):Doc12.

65. Aktekin M, Karaman T, Senol YY, Erdem S, Erengin H, Akaydin M. Anxiety, depression and stressful life events among medical students: a prospective study in Antalya, Turkey. Med Educ. 2001;35(1):12-7.

66. Liu XC, Oda S, Peng X, Asai K. Life events and anxiety in Chinese medical students. Soc Psychiatry Psychiatr Epidemiol. 1997:32(2):63-7.

67. Cohen S. Social relationships and health. Am Psychol. 2004;59(8):676-84.

68. Xiaowen W, Guangping G, Ling Z, Jiarui Z, Xiumin L, Zhaogin L, et al. Depression and anxiety mediate perceived social support to predict healthrelated quality of life in pregnant women living with HIV. AIDS Care. 2018; 30(9): $1147-55$

69. Ball S, Bax A. Self-care in medical education: effectiveness of health-habits interventions for first-year medical students. Acad Med. 2002;77(9):911-7.

70. Kjeldstadli K, Tyssen R, Finset A, Hem E, Gude T, Gronvold NT, et al. Life satisfaction and resilience in medical school--a six-year longitudinal, nationwide and comparative study. BMC Med Educ. 2006;6:48.

71. Souza RA, Desani da Costa G, Yamashita CH, Amendola F, Gaspar JC, Alvarenga MR, et al. Family functioning of elderly with depressive symptoms. Rev Esc Enferm USP. 2014:48(3):469-76.

72. Wickrama KA, Wickrama KA. Family context of mental health risk in tsunami affected mothers: findings from a pilot study in Sri Lanka. Soc Sci Med. 2008;66(4):994-1007.

73. Beutler LE, Moos RH, Lane G. Coping, treatment planning, and treatment outcome: discussion. J Clin Psychol. 2003;59(10):1151-67.

74. Zhao X, Wu M, Zhang D, Sun Y, Yang Y, Xie H, et al. The relationship of interpersonal sensitivity and depression among patients with chronic atrophic gastritis: the mediating role of coping styles. J Clin Nurs. 2018;27(5-6):e984-91.

75. Faisal-Cury A, Savoia MG, Menezes PR. Coping style and depressive symptomatology during pregnancy in a private setting sample. Span J Psychol. 2012;15(1):295-305.

76. Blake SM, Murray KD, El-Khorazaty MN, Gantz MG, Kiely M, Best D, et al. Environmental tobacco smoke avoidance among pregnant AfricanAmerican nonsmokers. Am J Prev Med. 2009;36(3):225-34.

77. Nolen-Hoeksema S, Morrow J. A prospective study of depression and posttraumatic stress symptoms after a natural disaster: the 1989 Loma Prieta earthquake. J Pers Soc Psychol. 1991;61(1):115-21.

78. Nolen-Hoeksema S, McBride A, Larson J. Rumination and psychological distress among bereaved partners. J Pers Soc Psychol. 1997;72(4):855-62

\section{Publisher's Note}

Springer Nature remains neutral with regard to jurisdictional claims in published maps and institutional affiliations.

\section{Ready to submit your research? Choose BMC and benefit from:}

- fast, convenient online submission

- thorough peer review by experienced researchers in your field

- rapid publication on acceptance

- support for research data, including large and complex data types

- gold Open Access which fosters wider collaboration and increased citations

- maximum visibility for your research: over $100 \mathrm{M}$ website views per year

At BMC, research is always in progress.

Learn more biomedcentral.com/submissions 